Article

\title{
The Role of Corporate Culture in Performance Measurement and Management Systems
}

\author{
Michaela Kotkova Striteska *(1) and David Zapletal 1 \\ Faculty of Economics and Administration, University of Pardubice, 53210 Pardubice, Czech Republic; \\ david.zapletal@upce.cz \\ * Correspondence: michaela.kotkovastriteska@upce.cz
}

Received: 3 November 2020; Accepted: 23 November 2020; Published: 27 November 2020

\begin{abstract}
Recently, there has been increasing pressure to change current performance measurement and management systems from control systems to those that support learning and continuous improvement. This change requires a specific corporate culture that supports the effective operation of performance measurement and management. This paper aims to clarify the relationship between corporate culture and performance measurement and management systems. Questionnaire survey data from Czech medium and large companies were collected and analyzed by Pearson's chi-squared test to validate the proposed hypothesis. The research findings confirmed that performance measurement and management systems of companies that devoted sufficient energy and attention to performance-driven culture are more effectively developed. Analysis of different performance-driven culture attributes revealed which are the most important ones.
\end{abstract}

Keywords: performance measurement system; performance management; performance-driven culture

JEL Classification: M14

\section{Introduction}

In a dynamic, rapidly changing environment, measuring and managing performance effectively is becoming one of the main challenges for companies (Micheli and Mura 2017; Yadav and Sagar 2013; Prokop et al. 2018). In the past two decades, several scientific studies have been conducted that have addressed various aspects of performance measurement: the extent of measurement utilization (Gómez et al. 2011; Robinson et al. 2005), the definition of performance measurement systems (Franco-Santos et al. 2007; Bourne 2005), the development and implementation of performance measurement systems (Atkinson 2012; Robinson et al. 2005), or new trends (Yadav and Sagar 2013; Marr and Schiuma 2003). Current research has focused more on performance measurement's technical aspects than behavioral aspects of performance management (De Waal 2004).

Kennerley and Neely (2003) state that only a few companies have a systematic process to manage their performance measurement systems development to reflect the organizational context. Henri (2006) adds that there is no single theory or clear consensus on the factors and contexts that influence the implementation and continuous improvement of performance measurement systems. Therefore, attention needs to be focused on how to change the approach of companies from mere measurement to performance management (Bititci et al. 2012). The current dominant paradigm in performance measurement and management (PMM), founded in the control systems literature, is beginning to be questioned to emphasize the potential inadequacy of existing approaches (Bourne et al. 2018).

According to Hamel (2009), the current command-and-control systems increases employee fear and reduce trust and employee engagement. In terms of system thinking, Seddon (2008) believes that 
performance indicators and their target values create a culture of command and control that often generates hidden interests and demoralizes people. Marr (2009) and Davenport (2006) emphasize the need to move away from control, order, and reporting systems that monitor delayed, pseudo-relevant indicators used to punish employees and move to systems that support organizational learning.

Therefore, it is necessary to examine the factors that significantly affect the effective operating of the PMM system. However, very few studies address this topic (Taylor and Taylor 2014; Hassan et al. 2020). In the literature, corporate culture is considered the main factor in the successful use of PMM (Atkinson 2012; Garengo and Bittitci 2007). We can assume that companies that pay enough attention and energy to a performance-driven corporate culture will have a more developed PMM. To date, there are very little empirical data that would explicitly confirm the relationship between the PMM system and corporate culture (Jardioui et al. 2017; Smith and Bititci 2017). The paper aims to fill this research gap and empirically examine the relationship between these two factors.

By clarifying the links between various attributes of corporate culture and performance measurement and management systems, the research study responds to recent studies' call (Bititci et al. 2018; Bourne et al. 2018) for a more systematic approach to the development of performance management theories. Our findings confirm that behavioral aspects influence the PMM system development and contribute to understanding performance measurement as an integrated social system in a constantly evolving context.

The rest of the paper is organized as follows. First, the theoretical background explains the relationship between the PMM system and corporate culture and identifies performance-driven culture's main characteristics. Second, research design and methodology are introduced. Third, the results and discussion are presented. In conclusion, the managerial implications in light of the main findings are drawn.

\section{Theoretical Background and Hypothesis}

PMMs do not operate in an organizational, strategic, or environmental vacuum. However, despite the increased need for measurement and consistent process management, it is still unclear which factors influence their successful development, implementation, and use in practice (Blasini and Leist 2013). Recently, one of the most frequently mentioned factors is a performance-driven corporate culture (Bititci et al. 2006; Garengo and Bittitci 2007; Franco-Santos and Bourne 2005).

Recently, the understanding of corporate culture concept has been dramatically improved. Groysberg et al. (2018) identified four generally accepted features of a corporate culture based on the seminal works of leading scholars: shared (culture is a group phenomenon), pervasive (culture permeates all levels, which is reflected in collective behavior), enduring (culture can control members' ideas and actions in the long term), and implicit (it is challenging for people to recognize and respond to culture instinctively; it acts as a kind of silent language). Culture is also recognized as a crucial input parameter in value-adding management theories (Van der Voordt et al. 2016).

\subsection{The Impact of Corporate Culture on Performance Measurement and Management Systems}

Jardioui et al. (2017) state that research studies on the impact of corporate culture on performance measurement systems can be divided into three streams. The first stream discusses the impact of corporate culture on PMM in general and states that the relationship between them is dyadic. The second stream suggests that the successful implementation of PMM requires a particular corporate culture (performance-driven culture), and the third direction focuses on specific components of corporate culture (e.g., types of culture) and PMM (e.g., diversity of measurement) (Jwijati and Bititci 2014).

Bourne et al. (2002), using system dynamics and so-called action research, identified two drivers (management commitment, awareness of the benefits provided by PMM) and four blockers (time and effort, difficulty in implementing performance indicators caused by inappropriate information available from IT systems, resistance to performance measurement, new parent company initiatives) as critical forces influencing the success or failure of PMM implementation. Chan (2004) states that the top 
management commitment and leadership are key factors in increasing the effectiveness of PMM. In this context, Nudurupati et al. (2011) and Davenport et al. (2010) point out several problems during PMM use when senior management commitment is lacking. The issues with change management, such as the resistance of people who often do not understand the goals and potential benefits, mean management tends to use PMM as a control and command mechanism.

Besides, Kennerley and Neely (2003) add other aspects of corporate culture that influence the development of PMM, namely the need to adopt continuous development, effective communication of performance indicators, the use of indicators for immediate action to think about strategies and processes, and open and fair use of performance indicators. Franco-Santos and Bourne (2005) consider a corporate culture that does not punish people's mistakes but encourages discussion and analysis of performance indicators to be a prerequisite for successful implementation. Several studies have also confirmed the relationship between employee participation and the effectiveness of PMM (Chan 2004; Tung et al. 2011). According to Assiri et al. (2006), one of the main factors increasing the successful implementation of PMM is a culture that stimulates all employees' participation and involvement.

Bititci et al. (2006) also examined the relationship between corporate culture, management style, and performance measurement. The key finding of their analysis is that the management style must evolve with the maturity of PMM and corporate culture. Successfully implemented and used PMM leads to a more participatory and consultative management style and the emergence of a culture of success. Atkinson (2012) reiterates the importance of visible leadership, commitment, and support of top management, as well as the ability to learn from mistakes and adapt to changing circumstances, consistent communication and demonstration of the values provided by the performance measurement system, the use of a single language for performance management and last but not least, the need to give managers and employees flexibility and independence in adjusting behavior based on information from the PMM. Thus, it is clear that behavioral factors are crucial, especially in the PMM usage phase (Elzinga et al. 2009).

\subsection{Performance-Driven Culture Characteristics}

To date, to our best knowledge, few research studies consider the main characteristics of performance-driven culture. Marr (2009) defines performance-driven culture as an environment where people are continually striving to learn and improve. At the very core of such oriented culture lies continuous improvement and learning. Similarly, De Waal and Counet (2009) have proved that the successful implementation and use of PMM requires a culture of continuous improvement. The importance of organizational learning for performance is also emphasized by Jones (2000). He defines it as the process of obtaining information, interpreting information fully to understand its significance, and implementing the resulting behavioral and cognitive changes that, in turn, affect performance. Behavioral and cognitive changes mean transforming words into deeds and seizing the opportunities that these changes bring.

Furthermore, Jardioui et al. (2017) found in their research that companies with a flexible culture tend to use a more balanced set of performance measures and PMM to meet learning goals, improving and implementing strategy. On the other hand, companies with a culture of control use PMM for monitoring and legitimization, mostly based on financial measures. Control and flexibility represent two competitive values considered corporate culture attributes (Cameron and Quinn 1999). Control values relate to predictability, stability, formality, rigidity, and agreement, while flexibility values relate to spontaneity, change, openness, adaptability, and sensitivity (Henri 2006). According to Amaratunga and Baldry (2002), a corporate culture of improvement and learning develops through participation, awareness, decentralized decision-making, and responsibility for achieving set goals during the performance management process.

Besides improvement and learning, Marr (2009) defines four other enablers of a performance-driven culture that are interconnected: the sense of belongingness and a common purpose, which strengthens participation, collaboration, and commitment; the demand for honesty and truth, which in turn 
creates trust and mutual respect; the acceptance of accountability, where individuals and groups of employees feel responsible for achieving results; and understanding of performance-driven culture importance throughout the company. Franco-Santos and Bourne (2005) add that the corporate culture critical to PMM success must emphasize teamwork, problem ownership, risk-taking, entrepreneurship, and encourage discussion and performance analysis without punishing people's mistakes.

Based on the theoretical model of Marr (2009), Nordiawan et al. (2017) determined five building blocks of a performance-driven culture: 1. leadership that encourages performance, 2. recognition and appreciation of the performance, 3. effective performance reporting, 4 . interactive performance reviews, and 5. a performance map. Lawson et al. (2013) illustrated and characterized Dresner's Performance Culture Maturity Model (Dresner 2009), which identified four performance-oriented culture maturity levels. If a performance-driven culture is genuinely implemented, the company has a stable position as a single unit in terms of thinking, strategy, planning, analysis, and implementation (taking corrective action). The model also sets out six crucial measurable criteria that help create a culture of performance: alignment with mission, transparency and accountability, information-based action, conflict resolution, shared trust in data, and the availability and dissemination of information (Lawson et al. 2013). A research study by Lawson et al. (2013) shows that only three of these six criteria are very important. These criteria are: the organization's alignment with its mission and vision, the presence of transparency and accountability, and the organization's ability to resolve conflicts effectively. The authors of the study described the other three criteria as less important.

The literature review results show that performance-driven culture contributes to eliminating several shortcomings of current PMMs. Above that, Smith and Bititci's (2017) recent research reveals that intervention in social control (corporate culture) leads to changes in the level of PMM technical control, which results in a significant improvement in employee engagement and performance. Therefore, we assume that the PMM system of companies building performance-driven culture will be more developed. To examine this assumption, performance-driven culture is operationalized into four attributes that most often define it (Kennerley and Neely 2003; Atkinson 2012): leadership focused on performance and visible commitment, consistent communication and demonstrating of the PMM system's benefits, the ability to learn from mistakes and adapt to a changing environment, using the information attained from the PMM system for strategy and processes revision. Companies that fulfill all four attributes are considered to be developing a performance-driven culture. Following these statements, the research hypotheses are formulated.

Hypothesis 1 (H1). The leadership focused on performance and visible top management commitment influences the level of PMM development.

Hypothesis $2 \mathbf{~ ( H 2 ) . ~ T h e ~ c o n s i s t e n t ~ c o m m u n i c a t i o n ~ a n d ~ d e m o n s t r a t i n g ~ t h e ~ P M M ~ s y s t e m ' s ~ b e n e f i t s ~ i n f l u e n c e ~}$ the level of PMM development.

Hypothesis 3 (H3). The ability to learn from mistakes and adapt to a changing environment influences the level of PMM development.

Hypothesis 4 (H4). Using information from performance measurement for strategy and processes revision influences the level of PMM development.

Hypothesis 5 (H5). The degree of performance-driven culture focus influences the level of PMM development.

\section{Research Design and Methodology}

The investigated sample consists of medium-sized and large companies (having more than 50 employees) from the five most competitive sectors in the Czech Republic (chemical and pharmaceutical industries, banking and insurance, electricity, gas, steam and air conditioning, electronic, optical 
products, and electrical equipment and the manufacture of motor vehicles). Medium-sized and large companies were selected because previous research proved that their PMM systems are more developed (Striteska et al. 2016). The population was identified using the Magnus Web database and included 1295 companies. Companies from the Czech Republic can present the current development of performance measurement and management in Central Europe.

A quantitative approach, the method of the electronic questionnaire, was used to gather data. The overall return rate was 10\%; 16 questionnaires were incomplete and 110 questionnaires were analyzed. The participants' sample can be described according to the number of employees and the type of ownership. According to the number of employees, the sample consisted of 50\% of companies with 50 to 250 employees, $15 \%$ of companies with 250 to 500 employees, and $35 \%$ of companies with more than 500 employees. According to the types of ownership, $46 \%$ of companies were domestic and $53 \%$ had foreign ownership, $1 \%$ of companies were state enterprises.

The questionnaire was divided into two parts. The first part was focused on finding out the current form of performance measurement and management systems. Four closed questions and one open question were raised to explore this area:

1. What components does your performance measurement system consist of?

2. In what proportion does your system contain financial and non-financial measures?

3. How do you examine the logical links among performance measures or strategic goals?

4. How often do you review the performance measures or strategic goals?

5. Can you describe the systematic process of strategy or performance measures review? The second part of the questionnaire found out whether the surveyed companies use defined attributes to build a performance-driven culture with the help of a semi-closed question:

6. How do you create a corporate culture focused on performance, improvement, and learning? The attributes we examined were predefined for the answers, but the companies could add additional ones. Besides, the use of the fourth attribute strategy and process revision was conditional on the completion of question number five.

The compiled questionnaire was pilot tested with two practitioners and subsequently sent by email with a request letter to the controlling or quality control department's middle management. In consideration of incentives for answering the questionnaire, it was clarified that a report on the research findings would be sent to the respondents. To improve the collection rate, a reminder was sent twice before the collection deadline. Even though our overall response rate was lower than it has been documented in similar scientific studies, the number of questionnaires obtained still allowed us to perform the intended analyses. A specialized research topic, which many managers consider an elusive issue, may have caused a lower response rate.

Pearson's chi-squared test was used to test the hypotheses concerning the random variable's independence. The test's statistics have the form

$$
\chi^{2}=\sum_{j=1}^{s} \sum_{i=1}^{r} \frac{\left(O_{i j}-E_{i j}\right)^{2}}{E_{i j}}
$$

where $r$ and $s$ are the numbers of categories of the investigated random variables, and $O_{i j}$ and $E_{i j}$ denote the observed and the theoretical frequencies, respectively. The null hypothesis concerning the independence of random variables is rejected if, for the given level of significance $\alpha$, the test's statistics (1) are greater than (or equal) to the $(1-\alpha)$-quantile of the chi-squared probability distribution with $(r-1) \cdot(s-1)$ degrees of freedom. In that case, the $p$-value, which is provided by most statistical software, is less than (or equal) the level of significance $\alpha$. 
Cramer's coefficient $V$ was used to assess the level of demonstrated dependence (association). The term gives the coefficient

$$
V=\sqrt{\frac{\chi^{2}}{n \cdot h}},
$$

where $n$ is the overall number of units included in the sample, and $h$ denotes the minimum of the numbers $(r-1)$ and $(s-1)$.

Moreover, in cases when it made sense to judge whether the intensity of dependence for the investigated value was comparable for both directions, we used Somers' $d$. It is an asymmetrical measure evaluating the directional dependence of the investigated values, where $d(X \mid Y)$ means the dependence of $Y$ on $X$ and $d(X \mid Y)$ vice versa.

\section{Results and Discussion}

Before addressing the relationship between effective PMM development and selected performance-driven attributes, it was necessary to evaluate the examined companies' PMM systems. This evaluation was performed based on the components that the current PMM in the company met. These components were defined by the help of existing frameworks to evaluate PMM system effectiveness (Tangen 2005; Henri 2006) and characteristics that an effective PMM system should fulfil (Nita 2011). The highly developed PMM system has to contain nine components: mission, vision, strategic goals, a balanced set of performance indicators, defining links among strategic goals or performance indicators, target values, cascading into individual goals and benchmarks, link to the remuneration system, and strategy revision. Companies with a PMM system containing 1 to 3 components were identified as enterprises with a low development level. Companies with 3 to 6 components had a medium level of PMM system development, and enterprises with 7 to 9 components had a highly developed PMM system.

Table 1 presents the frequencies of companies that devote energy to performance-focused leadership and visible commitment within each category of PMM system development.

Table 1. Contingency table of absolute and relative (as \% of the total) frequencies of performance measurement and management (PMM) system development level and leadership and commitment.

\begin{tabular}{ccccccc}
\hline \multirow{2}{*}{ Development Level } & \multicolumn{3}{c}{ Leadership and Commitment } & \multicolumn{2}{c}{ Total } \\
\cline { 2 - 5 } & \multicolumn{3}{c}{ YES } & \multicolumn{2}{c}{ NO } & \multicolumn{2}{c}{} \\
\hline Low & 8 & $7.27 \%$ & 16 & $14.55 \%$ & 24 & $21.82 \%$ \\
Intermediate & 22 & $20.00 \%$ & 37 & $33.64 \%$ & 59 & $53.64 \%$ \\
High & 17 & $15.45 \%$ & 10 & $9.09 \%$ & 27 & $24.55 \%$ \\
Total & 47 & $42.73 \%$ & 63 & $57.27 \%$ & 110 & $100.00 \%$ \\
\hline
\end{tabular}

The value of Pearson's chi-squared test of independence (1) is $\chi^{2}=6.913$. The corresponding $p$-value is $p=0.047$, which leads to the rejection (on 0.05 level of significance) of the statistical hypothesis of independence. The corresponding Cramer's coefficient (2) $V=0.235$ indicates (according to De Vaus [1985] 2002) low to medium dependence. Thus, we can state that the research Hypothesis H1 was confirmed.

This result is in accord with Chan's (2004), Marr's (2009), and Atkinson's (2012) statements, who considered leadership focused on performance and top management's visible commitment as the effectiveness-enhancing factors of PMM operation. Moreover, Hassan et al. (2020) recently empirically confirmed that leadership has had a significant positive effect on introducing the construction industry's performance measurement system. The reason may be that effective leadership (leading organization, leading people, and leading self) contributes to elevated trust and openness among people and promotes the successful implementation of knowledge management processes (Koohang et al. 2017). The culture of trust and mutual respect creates an environment where discussions and performance analyses can take place. 
Marr (2009) states that in organisations unable to engage people in dialogue and make them reflect on performance, no learning will ever take place. Therefore, how companies communicate the performance is crucial for successful performance management. Table 2 shows how many companies are trying to create a performance-driven culture by consistent communication and demonstrating the PMM system's benefits within each category.

Table 2. Contingency table of absolute and relative (as \% of the total) frequencies of PMM system development level and consistent communication and benefits.

\begin{tabular}{ccccccr}
\hline \multirow{2}{*}{ Development Level } & \multicolumn{3}{c}{ Communication and Benefits } & \multicolumn{2}{c}{ Total } \\
\cline { 2 - 5 } & \multicolumn{2}{c}{ YES } & \multicolumn{2}{c}{ NO } & & \\
\hline Low & 3 & $2.73 \%$ & 21 & $19.09 \%$ & 24 & $21.82 \%$ \\
Intermediate & 13 & $11.82 \%$ & 46 & $41.82 \%$ & 59 & $53.64 \%$ \\
High & 19 & $17.27 \%$ & 8 & $7.27 \%$ & 27 & $24.55 \%$ \\
Total & 35 & $31.82 \%$ & 75 & $68.18 \%$ & 110 & $100.00 \%$ \\
\hline
\end{tabular}

In this case, the value of Pearson's testing criteria is $\chi^{2}=25.223$, and the corresponding $p$-value is almost zero, which leads to the rejection of the statistical hypothesis of independence. Cramer's coefficient $V=0.479$ indicates a medium to significant dependence. Based on these results, we can argue that research hypothesis $\mathrm{H} 2$ is confirmed. PMM development level is influenced by how companies communicate and demonstrate the benefits that PMM brings them. This result verifies that communication is a critical aspect of performance-driven culture. Communication provides an understanding of policies, strategies, guidelines, and information across the enterprise. Furthermore, a comprehensive performance measurement system is richer in information and provides complete feedback about operations and results (Chenhall 2005). If the changes are not sufficiently communicated, barriers to creating and implementing innovations arise (Halaskova et al. 2018; Kotkova Striteska and Prokop 2020).

On the other hand, accurate information about business goals, policies, strategies, values, and practices improves communication. Likewise, established and anchored values and procedures facilitate feedback on individual activities and rapid responses to any deviations from performance (Gochhayat et al. 2017). Communication of information obtained from performance measurement is essential for understanding its significance and introducing behavioral changes (Jones 2000).

Learning from mistakes and adapting to changing circumstances is crucial for the PMM system remaining useful over time. According to Salloum and Wiktorsson (2009), continuous management of performance measurement means not only adding extra indicators as priorities change but also removing old priorities. A flexible performance measurement framework will allow us to look to the future and measure those factors that will lead to value creation tomorrow, rather than those that have created value in the past. Table 3 presents the results of the performance-driven culture attribute of the ability to learn from mistakes and adapt to changing environments.

Table 3. Contingency table of absolute and relative (as \% of the total) frequencies of PMM system development level and ability to learn from mistakes and adapt to change.

\begin{tabular}{crrrrrr}
\hline \multirow{2}{*}{ Development Level } & \multicolumn{3}{c}{ Learning and Change } & \multicolumn{2}{c}{ Total } \\
\cline { 2 - 5 } & \multicolumn{2}{c}{ YES } & \multicolumn{2}{c}{ NO } & & \\
\hline Low & 16 & $14.55 \%$ & 8 & $7.27 \%$ & 24 & $21.82 \%$ \\
Intermediate & 50 & $45.45 \%$ & 9 & $8.18 \%$ & 59 & $53.64 \%$ \\
High & 21 & $19.09 \%$ & 6 & $5.45 \%$ & 27 & $24.55 \%$ \\
Total & 87 & $79.09 \%$ & 23 & $20.91 \%$ & 110 & $100.00 \%$ \\
\hline
\end{tabular}

The value of Pearson's test statistic is $\chi^{2}=3.409$, and the corresponding $p$-value is $p=0.182$, which means that we cannot reject the statistical hypothesis of independence. Subsequently, the research 
hypothesis H3 cannot be confirmed. The reason may be that most of today's PMM systems are obsolete and static; they are not dynamic and sensitive to changes in the company's internal and external environment (Nudurupati et al. 2011). As a result, the information they provide is not current, relevant, or accurate. Exploring how companies strive for sufficient dynamism in their PMM system is considered critical for future performance management research (Franco-Santos et al. 2007).

More precisely, the PMM system must be regularly reviewed and updated to remain dynamic, flexible, and credible (Atkinson 2012). Consequently, it is necessary to test the influence of using information from performance measurement for strategy and process revision. Table 4 shows the frequencies of the fourth performance-driven attribute.

Table 4. Contingency table of absolute and relative (as \% of the total) frequencies of PMM system development level and strategy and process revision.

\begin{tabular}{ccccccc}
\hline \multirow{2}{*}{ Development Level } & \multicolumn{4}{c}{ Strategy Revision } & \multicolumn{2}{c}{ Total } \\
\cline { 2 - 5 } & \multicolumn{2}{c}{ YES } & \multicolumn{2}{c}{ NO } & & \\
\hline Low & 10 & $9.09 \%$ & 14 & $12.73 \%$ & 24 & $21.82 \%$ \\
Intermediate & 16 & $14.55 \%$ & 43 & $39.09 \%$ & 59 & $53.64 \%$ \\
High & 22 & $20.00 \%$ & 5 & $4.55 \%$ & 27 & $24.55 \%$ \\
Total & 48 & $43.64 \%$ & 62 & $56.36 \%$ & 110 & $100.00 \%$ \\
\hline
\end{tabular}

In this case, the value of Pearson's testing criteria is $\chi^{2}=22.306$, and the corresponding $p$-value is almost zero, which leads to the rejection of the statistical hypothesis of independence. Cramer's coefficient $V=0.450$ indicates a medium to significant dependence. The research hypothesis $\mathrm{H} 4$ is confirmed.

Finally, we tested all four performance-driven culture attributes to examine whether PMM systems that build this specific culture are more effectively developed. For this analysis, the examined companies were divided into three groups (see Table 5). The first group of companies indicated in the questionnaire survey paid attention to only one or two attributes. The reason for grouping these companies together was that possessing two attributes still meant that the companies devoted little attention to creating performance-driven culture. On the other hand, possessing all four attributes meant that companies wanted to use their PMM system as an instrument for learning and continuous improvement.

Table 5. Contingency table of absolute and relative (as \% of the total) frequencies of PMM system development level and all performance-driven culture attributes.

\begin{tabular}{|c|c|c|c|c|c|c|c|c|}
\hline \multirow{2}{*}{$\begin{array}{l}\text { Development } \\
\text { Level-X }\end{array}$} & \multicolumn{6}{|c|}{ Performance-Driven Culture Attributes- $Y$} & \multirow{2}{*}{\multicolumn{2}{|c|}{ Total }} \\
\hline & \multicolumn{2}{|c|}{$1-2$} & \multicolumn{2}{|c|}{3} & \multicolumn{2}{|c|}{4} & & \\
\hline Low & 14 & $12.73 \%$ & 9 & $8.18 \%$ & 1 & $0.91 \%$ & 24 & $21.82 \%$ \\
\hline Intermediate & 29 & $26.36 \%$ & 28 & $25.45 \%$ & 2 & $1.82 \%$ & 59 & $53.64 \%$ \\
\hline High & 3 & $2.73 \%$ & 13 & $11.82 \%$ & 11 & $10.00 \%$ & 27 & $24.55 \%$ \\
\hline Total & 46 & $41.82 \%$ & 50 & $45.45 \%$ & 14 & $12.73 \%$ & 110 & $100.00 \%$ \\
\hline
\end{tabular}

The value of Pearson's testing criteria is $\chi^{2}=30.913$, and the corresponding $p$-value is almost zero, which leads to the rejection of the statistical hypothesis of independence. Cramer's coefficient $V=0.375$ indicates a medium to significant dependence. These results confirm the acceptance of the research hypothesis $\mathrm{H} 5$, suggesting that companies that meet all attributes of a performance-driven culture have more developed PMM. In this case, it also made sense to evaluate the Sommers d one-sided dependencies. The values of the Sommers $d$ were comparable in both directions of the dependence $(d(X \mid Y)=0.384, d(Y \mid X)=0.383)$. This result complements the research hypothesis $\mathrm{H} 5$ confirmation and indicates that the relationship between variables is symmetric. We can also confirm that companies with effectively developed PMM should meet all four attributes of a performance-driven culture. 


\section{Conclusions}

The presented research study empirically tested the relationship between performance-driven culture and PMM system development. The results indicate that performance-driven culture is a critical factor that enhances the effectiveness of the PMM system. Our findings confirm and expand conclusions of previous research studies of Marr (2009), Nordiawan et al. (2017), and Atkinson (2012). According to our findings, the consistent communication and demonstration of PMM system benefits and the ability to use information from performance measurement for strategy and process revision are the attributes that most influence the PMM system development. It turns out that communication is indeed a critical factor in overcoming people's resistance and achieving a change in PMM system usage.

Likewise, leadership focused on performance and visible top management commitment belongs among attributes that influence the PMM system development. Company adaptability, innovation, and employee engagement can only thrive in a high-trust, low-fear culture (Hamel 2009; Klímová 2018; Prokop and Stejskal 2019). The only attribute for which the influence has not been confirmed is the ability to learn from mistakes and adapt to change. The question remains whether this factor is not so crucial for performance-driven culture creation or whether its significance has not yet been recognized in practice.

Concerning limitations, the study is subject to the usual constraints of the questionnaire survey method. Further, the results provide empirical evidence concerning the association between four performance-driven culture attributes and PMM system effectiveness. The lower response rate limits the generalizability of the findings. Future research should examine this question and consider additional factors, such as employee participation and engagement, teamwork, or risk-taking. Qualitative studies can investigate more deeply the characteristics of performance-driven culture and the mechanisms for its implementation in practice.

The findings of our study provide managers with an insight into the desirable characteristics of comprehensive PMM systems and the specific attributes of performance-driven culture that they can focus on to enhance the effectiveness of their performance measurement system. In this context, transformational leadership has been often mentioned in recent years. Kroll and Vogel (2014) believe that this leadership style is suitable for performance-driven culture because it combines charismatic influence, inspirational motivation, intellectual stimulation, and individualized thinking to convince followers of the added value of their work. From a theoretical perspective, the results empirically confirmed the relationships between effectively developed PMM systems and various corporate culture attributes. They also revealed that more future research within this field is needed.

Author Contributions: M.K.S. contributed to the literature review, data collection, discussion of results, and conclusions. D.Z. contributed to data analysis and evaluation. All authors have read and agreed to the published version of the manuscript.

Funding: This research received no external funding.

Conflicts of Interest: The authors declare no conflict of interest.

\section{References}

Amaratunga, Dilanthi, and David Baldry. 2002. Moving from performance measurement to performance management. Facilities 20: 217-23. [CrossRef]

Assiri, Ali, Mohammed Zairi, and Riyad Eid. 2006. How to profit from the balanced scorecard. Industrial Management \& Data Systems 106: 937-52.

Atkinson, Maurice. 2012. Developing and using a performance management framework: A case study. Measuring Business Excellence 16: 47-56. [CrossRef]

Bititci, Umit S., Kepa Mendibil, Sai Nudurupati, Patrizia Garengo, and Trevor Turner. 2006. Dynamics of performance measurement and organizational culture. International Journal of Operations and Production Management 26: 1325-50. [CrossRef] 
Bititci, Umit S., Patrizia Garengo, Viktor Dörfler, and Sai Nudurupati. 2012. Performance measurement: Challenges for tomorrow. International Journal of Management Reviews 14: 305-27. [CrossRef]

Bititci, Umit S., Mike Bourne, Jennifer A. Cross, Sai S. Nudurupati, and Kate Sang. 2018. Towards a theoretical foundation for performance measurement and management. International Journal of Management Reviews 20: 653-60. [CrossRef]

Blasini, Josef, and Susanne Leist. 2013. Success factors in process performance management. Business Process Management Journal 19: 477-95. [CrossRef]

Bourne, Mike. 2005. Researching performance measurement system implementation: The dynamics of success and failure. Production Planning \& Control 16: 101-13.

Bourne, Mike, Andy Neely, Ken Platts, and John Mills. 2002. The success and failure of performance measurement initiatives. International Journal of Operations \& Production Management 22: 1288-310.

Bourne, Mike, Steven Melnyk, and Umit S. Bititci. 2018. Performance measurement and management: Theory and practice. International Journal of Operations \& Production Management 38: 2010-21.

Cameron, Kim, and Rober E. Quinn. 1999. Diagnosing and Changing Organizational Culture: Based on the Competing Values Framework. Reading: Addison-Wesley.

Chan, Yee-Ching Lilian. 2004. Performance measurement and adoption of balanced scorecards: A survey of municipal governments in the USA and Canada. International Journal of Public Sector Management 17: $204-21$. [CrossRef]

Chenhall, Robert H. 2005. Integrative strategic performance measurement systems, strategic alignment of manufacturing, learning and strategic outcomes: An exploratory study. Accounting Organizations and Society 30: 395-422. [CrossRef]

Davenport, Thomas H. 2006. Competing on Analytics. Harvard Business Review 84: 98-107.

Davenport, Thomas H., Jeanne G. Harris, and Robert Morison. 2010. Analytics at Work: Smarter Decisions, Better Results. Boston: Harvard Business Press.

De Vaus, David. 2002. Surveys in Social Research, 5th ed. Abingdon: Psychology Press, p. 379. First published 1985.

De Waal, A. Andre. 2004. Stimulating performance-driven behaviour to obtain better results. International Journal of Productivity and Performance Management 53: 301-16. [CrossRef]

De Waal, A. Andre, and Harold Counet. 2009. Lessons learned from performance management systems implementations. International Journal of Productivity and Performance Management 58: 367-90. [CrossRef]

Dresner, Howard. 2009. Profiles in Performance: Business Intelligence Journeys and the Roadmap for Change. Hoboken: John Wiley \& Sons.

Elzinga, Taco, Bé Albronda, and Frits Kluijtmans. 2009. Behavioral factors influencing performance management systems' use. International Journal of Productivity and Performance Management 58: 508-22. [CrossRef]

Franco-Santos, Monika, and Mike Bourne. 2005. An examination of the literature relating to issues affecting how companies manage through measures. Production Planning and Control 16: 114-24. [CrossRef]

Franco-Santos, Monica, Mike Kennerley, Pietro Micheli, Veronica Martinez, Steve Mason, Bernard Marr, Diana Gray, and Andrew Neely. 2007. Towards a definition of a business performance measurement system. International Journal of Operations \& Production Management 27: 784-801.

Garengo, Patrizia, and Umit Bittitci. 2007. Towards a contingency approach to performance measurement: An empirical study in Scottish SMEs. International Journal of Operations and Production Management 27: 802-25. [CrossRef]

Gochhayat, Jyotiranjan, Vijai N. Giri, and Damodar Suar. 2017. Influence of organizational culture on organizational effectiveness: The mediating role of organizational communication. Global Business Review 18: 691-702. [CrossRef]

Gómez, Joaquín, Micaela Martínez Costa, and Ángel R. Martínez Lorente. 2011. A critical evaluation of the EFQM model. International Journal of Quality \& Reliability Management 28: 484-502.

Groysberg, Borsi, Jeremiah Lee, Jesse Price, and Yo-Jud J. Cheng. 2018. The leader's guide to corporate culture. Harvard Business Review 96: 44-52.

Halaskova, Martina, Renata Halaskova, and Viktor Prokop. 2018. Evaluation of efficiency in selected areas of public services in European Union countries. Sustainability 10: 4592. [CrossRef]

Hamel, Gary. 2009. Moon shots for management. Harvard Business Review 87: 91-98. [PubMed]

Hassan, Abdulwadod, Saeed Abdulwasea, Norshahrizan Nordin, and Adi Anuar Azamin. 2020. The Influence of the External and Internal Factors on the Adoption of the Performance measurement System in the Construction 
Industry in Yemen. Paper presented at IOP Conference Series: Materials Science and Engineering, 864, 2nd Joint Conference on Green Engineering Technology \& Applied Computing 2020, Bangkok, Thailand, February 4-5.

Henri, Jean-Francois. 2006. Organizational culture and performance measurement systems. Accounting Organizations and Society 31: 77-103. [CrossRef]

Jardioui, Meriam, Patrizia Garengo, and Semma El Alami. 2017. The impact of organizational culture on performance measurement system design, implementation and use: Evidence from moroccan SMEs. Paper presented at IFIP International Conference on Advances in Production Management Systems, Hamburg, Germany, September 3-7; Cham: Springer.

Jones, Gareth R. 2000. Organizational Theory. Upper Saddle River: Prentice Hall.

Jwijati, Ihssan M., and Umit S. Bititci. 2014. Exploring the impact of national culture on performance measurement. Paper presented at IFIP International Conference on Advances in Production Management Systems, Ajaccio, France, September 20-24; Berlin: Springer, pp. 425-32.

Kennerley, Mike, and Andy Neely. 2003. Measuring performance in a changing business environment. International Journal of Operations and Production Management 23: 213-29. [CrossRef]

Klímová, Viktorie. 2018. How do regions use indirect R\&D support for their innovation activities? Scientific papers of the University of Pardubice. Series D, Faculty of Economics and Administration 42: 104-15.

Koohang, Alex, Joanna Paliszkiewicz, and Jerzy Goluchowski. 2017. The impact of leadership on trust, knowledge management, and organizational performance. Industrial Management E Data Systems 117: 521-37.

Kotkova Striteska, Michaela, and Viktor Prokop. 2020. Dynamic Innovation Strategy Model in Practice of Innovation Leaders and Followers in CEE Countries-A Prerequisite for Building Innovative Ecosystems. Sustainability 12: 3918. [CrossRef]

Kroll, Alexander, and Dominik Vogel. 2014. The PSM-leadership fit: A model of performance information use. Public Administration 92: 974-91. [CrossRef]

Lawson, Raef C. M. A., Toby Hatch, and Denis Desroches. 2013. How corporate culture affects performance management. Strategic Finance 94: 42, 44-50.

Marr, Bernard. 2009. Managing and Delivering Performance. London: Routledge.

Marr, Bernard, and Gianni Schiuma. 2003. Business performance measurement-past, present and future. Management Decision 41: 680-87. [CrossRef]

Micheli, Pietro, and Matteo Mura. 2017. Executing strategy through comprehensive performance measurement systems. International Journal of Operations \& Production Management 37: 423-43.

Nita, Bartłomiej. 2011. Performance Measurement and Management. Wrocław: Publishing House of Wrocław University of Economics.

Nordiawan, Deddi, Eko Prasodjo, and Sudarsono Hardjosoekarto. 2017. Reconstruction of performance-driven culture: Application of soft systems methodology at East Java Province, Indonesia. Paper presented at 16th European Conference on Research Methodology for Business and Management Studies, Dublin, Ireland, June 22-23; Dublin: Academic Conferences and Publishing International Limited, pp. 277-86.

Nudurupati, Sai S., Umit S. Bititci, Vikas Kumar, and Felix T. S. Chan. 2011. State of the art literature review on performance measurement. Computers \& Industrial Engineering 60: 279-90.

Prokop, Viktor, and Jan Stejskal. 2019. Determinants of innovation activities and SME absorption-Case study of Germany. Scientific Papers of the University of Pardubice. Series D, Faculty of Economics and Administration 46: 134-46.

Prokop, Viktor, Samuel Amponsah Odei, and Jan Stejskal. 2018. Propellants of University-Industry-Government synergy: Comparative study of Czech and Slovak manufacturing industries. Ekonomický časopis SAV 66: 987-1001.

Robinson, Herbert S., Chimay J. Anumba, Patricia M. Carrillo, and Ahmed M. Al-Ghassani. 2005. Business performance measurement practices in construction engineering organisations. Measuring Business Excellence 9: 13-22. [CrossRef]

Salloum, Mohammed, and Magnus Wiktorsson. 2009. From metrics to process: Towards a dynamic and flexible performance measurement system for manufacturing systems. Paper presented at SPS09, Goteborg, Sweden, December 2-3.

Seddon, John. 2008. Systems Thinking in the Public Sector. Axminster: Triarchy Press. 
Smith, Marisa, and Umit S. Bititci. 2017. Interplay between performance measurement and management, employee engagement and performance. International Journal of Operations \& Production Management 37: 1207-28.

Striteska, Michaela, David Zapletal, and Lucie Jelínková. 2016. Performance management systems in czech companies: Findings from a questionnaire survey. E+M. Economics and Management 4: 44-55. [CrossRef]

Tangen, Stefan. 2005. Analysing the requirements of performance measurement systems. Measuring Business Excellence 9: 46-54. [CrossRef]

Taylor, Andrew, and Margaret Taylor. 2014. Factors influencing effective implementation of performance measurement systems in small and medium-sized enterprises and large firms: A perspective from Contingency Theory. International Journal of Production Research 52: 847-66. [CrossRef]

Tung, Amy, Kevin Baird, and Herbert P. Schoch. 2011. Factors influencing the effectiveness of performance measurement systems. International Journal of Operations \& Production Management 31: 1287-310.

Van der Voordt, Theo, Per Anken Jensen, Hoendervanger Jan Gerard, and Feike Bergsma. 2016. Value Adding Management of buildings and facility services in four steps. Corporate Real Estate Journal 6: 42-56.

Yadav, Neetu, and Mahim Sagar. 2013. Performance measurement and management frameworks. Business Process Management Journal 19: 947-70. [CrossRef]

Publisher's Note: MDPI stays neutral with regard to jurisdictional claims in published maps and institutional affiliations.

(C) 2020 by the authors. Licensee MDPI, Basel, Switzerland. This article is an open access article distributed under the terms and conditions of the Creative Commons Attribution (CC BY) license (http://creativecommons.org/licenses/by/4.0/). 